\title{
Daidzein exerts anti-tumor activity against bladder cancer cells via inhibition of FGFR3 pathway
}

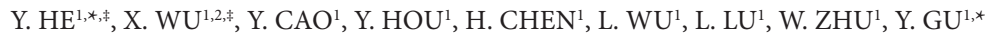 \\ ${ }^{1}$ Department of Urology, No. 1 hospital of Jiaxing, Jiaxing, Zhejiang, China; ${ }^{2}$ The 2nd Clinical Medical College, Zhejiang Chinese Medical \\ University, Hangzhou, Zhejiang, China \\ *Correspondence: alan_1015@163.com;jxdyyygyq@sina.com \\ *Contributed equally to this work.
}

Received May 23, 2015 / Accepted December 15, 2015

\begin{abstract}
Bladder cancer is one of the causes of cancer-related death and has a high mortality rate. Daidzein, a natural isoflavone compound predominantly extracted from soybeans, has been reported to exhibit several bioactivities, including anti-tumor. However, the effects of daidzein on bladder cancer remains unrevealed. Here we investigated the effects and molecular mechanisms of daidzein on bladder cancer using multiple in vitro cell lines and in vivo xenograft mice studies. Our results showed that daidzein reduced cell viability in a time- and concentration-dependent manner. Daidzein significantly impaired colony formation, caused G1/S cell cycle arrest and induced apoptosis of the bladder cancer cells. We also verified that daidzein efficiently suppressed RT112 cell xenograft tumor growth in nude mice. Mechanism studies indicated that significant down-regulation of the FGFR3 signaling pathway was responsible for the efficacy of daidzein. The phosphorylation levels of FGFR3, Akt and Erk proteins were suppressed in association with the decreasing of some apoptosis-suppressing molecules under the daidzein treatment. Knockdown of endogenous FGFR3 impaired the activity of daidzein against bladder cancer, which suggested that the effect of daidzein was mainly mediated by FGFR3 pathway. In addition, the function model of daidzein was similar with FGFR3 antagonist PD173074 in RT112 cells. Taken together, the results this study demonstrate that daidzein is capable of inhibiting bladder cancer growth and might be a novel effective chemotherapeutic agent for the application to combat bladder carcinoma.
\end{abstract}

Key words: bladder cancer, daidzein, tumor growth, FGFR3 signaling pathway

Bladder cancer is one of the most common malignancies of the genitourinary tract and ranks ninth in worldwide cancer incidence. The GLOBOCAN reported that approximately 429,000 new bladder cancer cases and 165,000 deaths occurred worldwide in 2012[1]. Despite radical cystectomy and chemotherapy, the 5-year survival rate for patients with local and distant metastatic bladder cancer is approximately $35 \%$ and $6 \%$, respectively[2]. Since severe side effects are invoked by most of the chemotherapy drugs, more attentions have been focused on natural compounds with minimal or no toxicity and having the notable efficacy on bladder cancer cells.

Normally, fibroblast growth factors (FGFs) act in concert with heparin or heparan sulfate proteoglycan (HSPG) to activate the fibroblast growth factor receptors (FGFRs). This facilitates the recruitment of critical adaptor proteins, such as FGFR substrate $2 \alpha($ FRS $2 \alpha)$, leading to activation of multiple signaling cascades such as MAPK and PI3K/Akt pathways to regulate a wide range of biological functions, such as cellular proliferation, survival, migration and differentiation [3-5].The FGFR signaling pathway could be constitutively activated by genetic alterations, which promote cell growth, angiogenesis, invasion and metastasis[6]. Previous studies have addressed the clinical relevance of FGFR3 alteration in bladder cancer development and prognosis and that FGFR3 was considered as a therapeutic target in the treatment of bladder cancer[7-9]. Thus, identifying a new anticancer drug targeting FGFR3signalingpathway is very promising for bladder cancer therapy.

Thesoy isoflavone, daidzein, is used as a phytoestrogen for treating cardiovascular disease[10], osteoporosis [11] and lower cholesterol[12]. Moreover, daidzein has been reported to inhibit the proliferation of human breast cancer MDAMB-453 cells [13] and cervical cancer Hela cells in vitro[14]. 
However, there are still gaps in current knowledge regarding their precise cellular and molecular mechanisms and the efficacy of daidzein on bladder cancer has not been revealed. In this study, the potential anticancer activity and inhibition of FGFR3 signaling as well as molecular events implicated in these activities were elucidated in human bladder cancer cells.

\section{Materials and methods}

Cells culture and reagents. Human bladder carcinoma cells (RT112, RT4and SW780) and immortalized normal human urothelial cells (SV-HUC-1) were cultured in DMEM high glucose and F12K medium containing $10 \%$ fetal bovine serum. Daidzein (purity $>99 \%$ ) was purchased from Shanghai TautoBiotech Co., Ltd. Antibodies specific for actin, FGFR3, p-FGFR3, Akt, p-Akt, Erk, p-Erk, Cyclin D1, c-Myc, Bcl-xl, Bcl-2, p21 were purchased from Cell Signaling Technology. CCK-8 detection kit was obtained from Dojindo Molecular Technologies. Annexin V-FITC/PI Apoptosis Detection Kit was purchased from BD. FGFR3 antagonist PD173074 was purchased from Sigma-Aldrich [15].

Cell viability assay. Bladder cancer cells $\left(5 \times 10^{3}\right.$ cells/well) seeded in 96-well plates were treated with various concentrations of daidzein for 48 hours or indicated time. Thereafter cell viability was assessed in triplicate with a CCK- 8 detection kit according to the manufacturer's instructions. The absorbance was measured at $450 \mathrm{~nm}$ on a plate reader (Thermo Fisher).

Colony formation assay. RT112 cells $\left(2 \times 10^{3}\right.$ cells/well $)$ seeded in 6-well dishes were allowed to attach overnight and then exposed to different concentrations of daidzein for 7 days. After fixed with $4 \%$ paraformaldehyde for 20 minutes at room temperature, cells were stained with $0.2 \%$ crystal violet. The morphology of cell colonies was recorded with photo imaging and the numbers of cell colonies were calculated. Triplicate wells were set up for each concentration.

Apoptosis assay. RT112 cells $\left(1 \times 10^{5}\right.$ cells/well $)$ seeded in 6-well plates were treated with daidzein for 36 hours then collected, washed with PBS for 3 times, and stained with Annexin V-FITC and propidium iodide (PI)with Annexin V-FITC Apoptosis Detection Kit I (BD Pharmingen) was pretreated for 15 minutes before evaluation by flow cytometry (FACSCalibur; BD Biosciences).

Cell cycle analysis. For cell cycle analysis, cells were exposed to different concentration of daidzein for 24 hours. After digested with trypsin, adherent and floating cells were collected, fixed in cold $70 \%$ ethanol overnight in $4^{\circ} \mathrm{C}$.After ethanol fixation, cells were washed once in PBS and stained with PI $(50 \mathrm{ng} / \mu \mathrm{l})$ containing ribonuclease A (50 ng/ $\mu \mathrm{l})$ at $37^{\circ} \mathrm{C}$ for 1 hour. Then cells were analyzed by flow cytometry (FACSCalibur; BD Biosciences).

Western blotting. Cells treated with indicated doses of daidzeinwere lysed in RIPA buffer ( $50 \mathrm{mM}$ Tris- $\mathrm{HCl}, \mathrm{pH} 7.2$, $150 \mathrm{mM} \mathrm{NaCl}, 1 \% \mathrm{NP} 40,0.1 \%$ SDS, 0.5\% DOC, 1 mM PMSF, $25 \mathrm{mM} \mathrm{MgCl}_{2}$, and supplemented with a phosphatase inhibitor cocktail). Whole samples were run on $8 \%$ to $12 \%$ SDS-PAGE gels and subjected to immunoblotting analysis with indicated antibodies.

In vivo xenograft experiments. Female nude mice (Bi-kai Biotech.) aged 5-week-old were used. RT112 cells $\left(1 \times 10^{6}\right.$ cells $)$ were suspended in Matrigel (BD Biosciences) and injected subcutaneously into the mice. Three days after seeding of the tumor cells, mice bearing evident tumors were randomly divided into control and daidzein treatment groups (five mice per group). Daidzein (10 mg/kg and $20 \mathrm{mg} / \mathrm{kg}$ ) was injected intraperitoneally once a day for 27 days and mice body weight were recorded every 3 days. The control group was treated with DMSO. Animals were euthanized with carbon dioxide, tumor masses were isolated and tumor weight was measured.

Small interfering (si) RNA for FGFR3. Small interfering RNAs (siRNAs) for FGFR3 (sc-29314) were purchased from Santa Cruz. RT112 cells were approximately $80 \%$ confluent at the time of transfection. SiRNA duplexes were transfected into cells using Lipofectamine ${ }^{\oplus}$ RAiMAX Reagent according to manufacturer's instructions. After 24 hours post transfection, the medium was replaced with fresh and the cells were incubated another 24 hours before lysed for Western blotting to test the knockdown effect of FGFR3.

Statistical analysis. Results were statistically analyzed using the Student's t test except that the statistical analysis of tumor volume grow with days was conducted with two-way ANOVA performed with Graphpad Prism 5 software was used to compare group means.. All experiments were repeated at least three times. A value of ${ }^{\star} P<0.05$ was considered statistically significant.

\section{Results}

Cytotoxicity of daidzein on human bladder carcinoma cells. The chemical structure of daidzein was shown in Figure 1A. To evaluate the cytotoxicity of daidzein on human bladder carcinoma cells (RT112, RT4 and SW780 cells) and further examine whether daidzein had ideal selective effects between bladder carcinoma cells and normal urothelial cells (SV-HUC-1 cells), cells were treated with various concentrations of daidzein for 48 hours, then cell viability was assessed with CCK- 8 assay. Treatment with daidzein at doses ranging between 0 and $100 \mu \mathrm{M}$ over a period of 48 hours was found to reduce cell viability of all indicated cell lines. As shown in Figure $1 \mathrm{~B}$, the half-maximum inhibiting concentrations $\left(\mathrm{IC}_{50}\right.$ value) for daidzein inhibition of bladder carcinoma cells' cellular proliferation were approximately $5-10 \mu \mathrm{M}$, while that of normal human urothelial cells (SV-HUC-1 cells) was much more than $100 \mu \mathrm{M}$, indicating daidzein was more toxic to cancer cells than to normal urothelial cells. Furthermore, daidzein not only significantly reduced cell viability in a dosedependent manner, but also in a time-dependent manner on bladder cancer cells as shown in Figure 1C.

Daidzein inhibits colony formation of bladder carcinoma cells. Next, colony formation assay was carried out to test the 
A<smiles>O=c1c(-c2ccc(O)cc2)coc2cc(O)ccc12</smiles>

Daidzein

$\mathrm{C}_{15} \mathrm{H}_{10} \mathrm{O}_{4} \mathrm{MW}: 254.24$

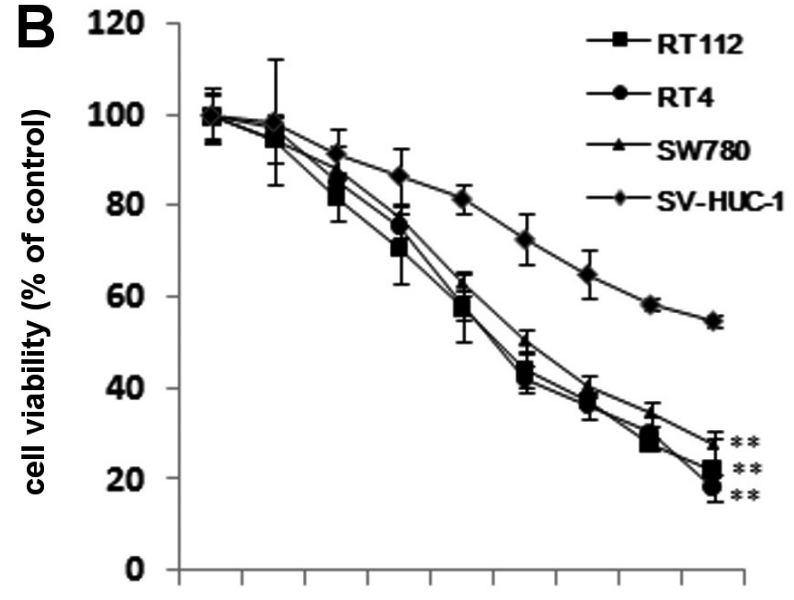

$\begin{array}{llllllllll}0 & 0.5 & 1 & 2.5 & 5 & 7.5 & 10 & 50 & 100\end{array}$ Daidzein $(\mu \mathrm{M})$
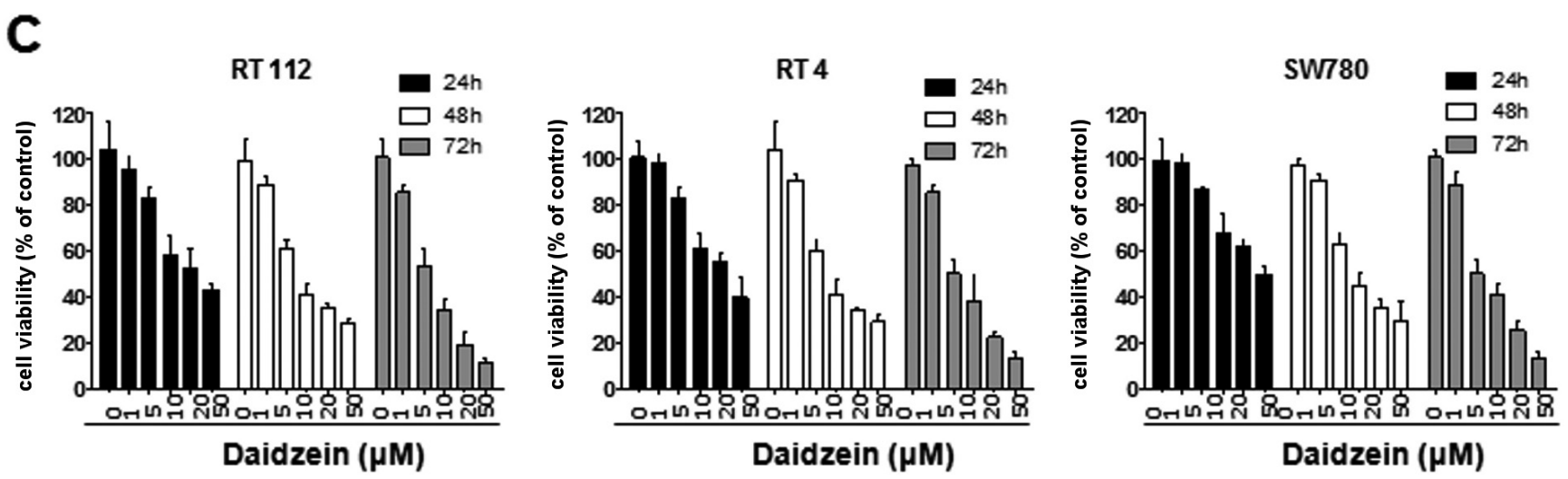

Figure 1. Daidzein suppresses cell viability of bladder carcinoma cells in a dose- and time-dependent manner.

(A) Chemical structure of daidzein. (B) Human bladder carcinoma cells (RT112, RT4and SW780) and immortalized normal human urothelial cells (SV-HUC-1) were treated with indicated concentrations of daidzein for 48 hours. Cell viability was assessed by CCK-8 detection kit. Data were presented as mean \pm SEM., $n=3,{ }^{*} P<0.05,{ }^{* *} P<0.01$.(C) Bladder carcinoma cells were treated with daidzein with indicated concentrations and hours to test the time- and dose-dependent effects.

inhibition effect of daidzein to cell proliferation of bladder carcinoma RT112cells. Cells seeded in 6-well dishes were exposed to various concentration of daidzein for 7 days. The morphology of cell colonies was recorded with photo imaging and the number of cell colonies were calculated and analyzed as the ratio of the number of treated samples to untreated sample. Compared to control treatment, the daidzein treatment at $10 \mu \mathrm{M}$ concentration caused a very significant decreased colony formation (Figure 2A). The according statistic result of colony formation assay was shown in Figure 2B. RT112 cells displayed a decreased number of colonies with the increase of daidzein concentration, suggesting daidzein inhibited colony formation of RT112 cells in a dose-dependent manner. When administrating daidzein on other types of bladder cancer cell lines (RT4 and SW780), similar results with RT112 were obtained (data not shown), which indicated that daidzein impairs colony formation of bladder carcinoma in vitro and might have inhibitory effects on bladder cancer growth.

Daidzein induces G1/S phase arrest and apoptosis of RT112 cells. To further investigate whether daidzein could influence cell cycle of bladder carcinoma cells, the RT112 cells were exposed to different concentration of daidzein for 24 hours and cell cycle distribution analysis was carried out by flow cytometry. As shown in Figure 2C, compared to the control group, a remarkable increase of $\mathrm{G} 1$ phase population was observed in daidzein-treated cells. This effect was shown in a daidzein dose-dependent manner. Statistically, daidzein increased cell numbers of RT112 cells at G1/S phase from $45 \%$ (control) to nearly $75 \%(10 \mu \mathrm{M})$ (Figure 2D).

Then we set out to investigate whether daidzein-induced cell cycle arrest could cause apoptosis and cell death of RT112 cells. Cell samples were treated with daidzein at $5 \mu \mathrm{M}$ and $10 \mu \mathrm{M}$ for 36 hours, then subjected to AnnexinV-FITC/PI staining for 
A

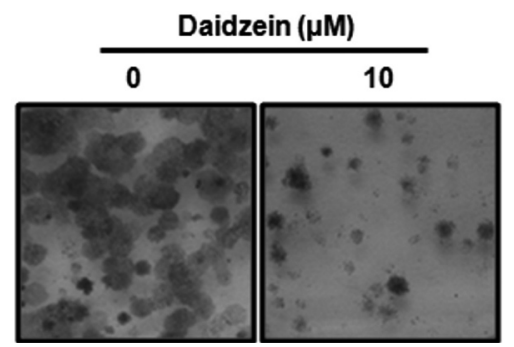

C

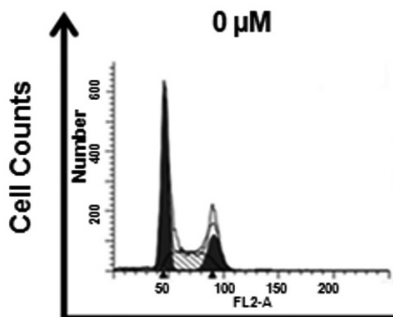

$5 \mu \mathrm{M}$

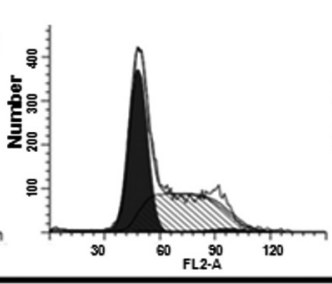

DNAContent
B

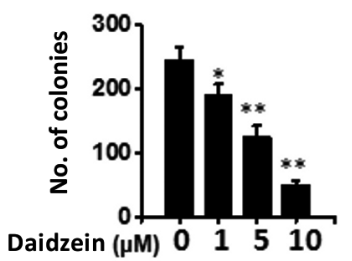

$\mathbf{E}$

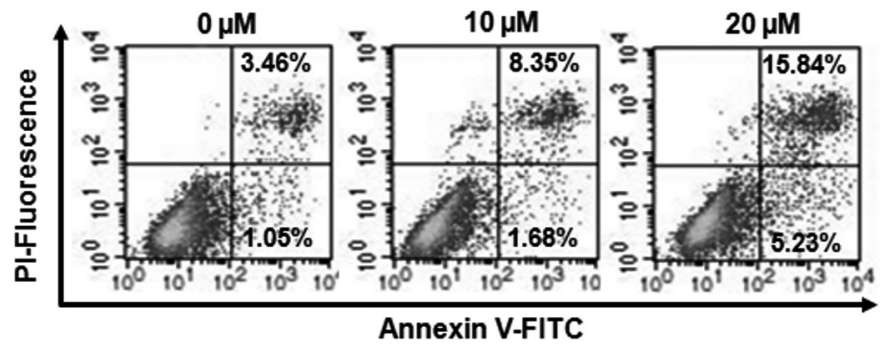

Figure 2. Daidzein inhibits RT112 cell colony formation and causes cell death through both inducing cell cycle arrest and intriguing cell apoptosis. (A, B) Bladder carcinoma RT112cellswere subjected to the colony formation assay and the result was photographed. RT112 cells were seeded in 6-well plates for 7 days after the treatment of daidzein in according concentrations and fixed with $4 \%$ paraformaldehyde, and stained with $0.2 \%$ crystal violet and the statistic results of colony formation was calculated. Data were presented as mean $\pm S E M$., $n=3,{ }^{*} P<0.05,{ }^{* *} P<0.01$. $(C, D) R T 112$ cells seeded in 6-well plates were treated with indicated concentrations of daidzein for $\mathbf{2 4}$ hours. After PI staining, cells were analyzed by flow cytometry for cell cycle analysis.(E) RT112 cells were treated with indicated concentrations of daidzein for 36 hours. Apoptosis and cell death were assessed by Annexin V/PI staining with flow cytometry.

apoptosis analysis. As shown in Figure 2E, in control group, the percentage of early apoptotic cell population was low (1.05\%), daidzeinat $5 \mu \mathrm{M}$ and $10 \mu \mathrm{M}$ incubation increased the early apoptotic percentage to $1.68 \%$ and $5.23 \%$, respectively. Meanwhile, cell death population increased in a daidzein dose-dependent manner, indicating daidzein caused cell apoptosis induction and led to cell death. Taken together, these results suggested daidzein could cause cell death of RT112 cells through inducing G1/S phase arrest and apoptosis.

Daidzein inhibits RT112 bladder tumor growth in vivo. From the in vitro colony formation assay we could speculate that daidzein may inhibit the growth of bladder cancer. To further evaluate the tumor-suppressing effect of daidzein in vivo, a model for tumorigenicity of bladder cancer RT112 cells in nude mice was established. After the treatment of daidzein for 27 days, images of the tumor in indicated groups along their mean tumor weights are shown in Figure $3 \mathrm{~A}$ and $3 \mathrm{~B}$. As anticipated, the tumor sizes of daidzein treatment groups were smaller than those of the control group, indicating the tumor inhibitory activity of daidzein. Remarkably, the average tumor masses in $20 \mathrm{mg} / \mathrm{kg}$ daidzein treatment group were approximately $19 \%$ of the control group. Moreover, no statistically significant difference in mouse body weight was detected among these three groups, suggesting a low toxicity of daidzein (Figure 3C). Taken together, these results suggested the administration of daidzein could therapeutically suppress bladder tumor growth in vivo, which was consistent with the in vitro cell lines' results. 
A

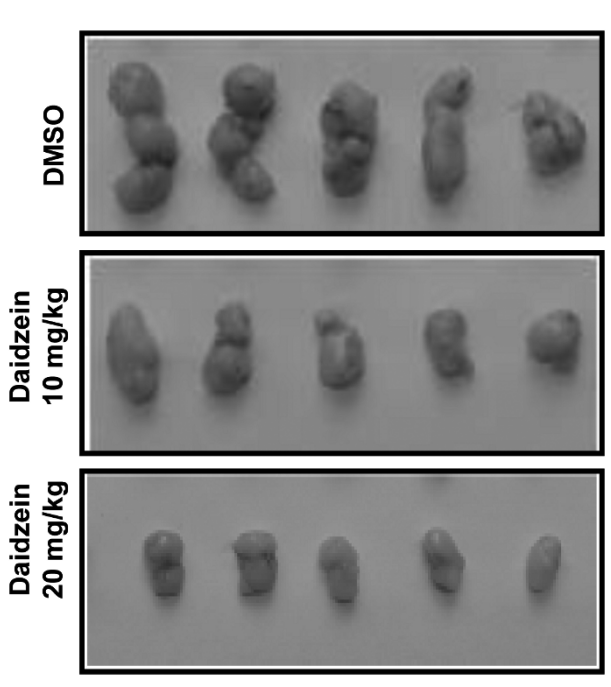

B

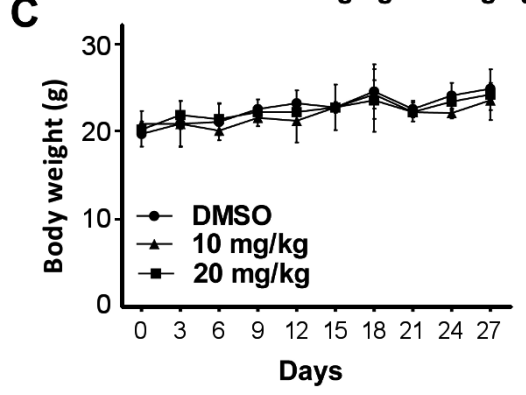

Figure 3. Daidzein inhibits RT112bladder tumor growth in vivo.

(A) Representative photos of nude mice bearing tumors formed by RT112 cells after daidzein (doses of daidzein at $10 \mathrm{mg} / \mathrm{kg}$ and $20 \mathrm{mg} / \mathrm{kg}$ ) administration, using those treated with DMSO as control. (B) Weight of the tumor masses dissected from the mice in indicated groups. Data were shown with mean \pm SEM, $n=5,{ }^{*} P<0.05,{ }^{*} P<0.01$.(C) Effects of daidzein treatments on mice body weight. Data were shown with mean \pm SEM, $n=5$.

Daidzein suppresses the FGFR3 signaling pathway in RT112 cells. To further examine whether daidzein could influence the FGFR3 signaling pathway, RT112 cells were pretreated with indicated concentrations of daidzein for 4 hours, and then incubated with $20 \mathrm{ng} / \mathrm{ml}$ of FGF1 for another 1 hour. The Western blotting result was shown in Figure 4A. After the stimulation with FGF1, the phosphorylation of FGFR3 remarkably increased and daidzein significantly inhibited this increase in a dose-dependent manner. Additionally, we found that FGF1 treatment activated the downstream signaling of FGFR3 protein, the phosphorylation levels of Akt and Erk increased accordingly in the same manner as p-FGFR, while the total amount of these signaling proteins kept steady. However, daidzein treatment blocked the FGF1-inducing effect and down-regulated all these signaling proteins' phosphorylation. These results indicated the fact that daidzein suppressed FGFR3 signaling pathways. On the other hand, RT112 cells were exposed to daidzein treatment at various concentrations. As shown in Figure 4B, daidzein indeed down-regulated both CyclinD1 and c-Myc protein levels in a dose-dependent manner, which led to cell cycle arrest. Moreover, p21 expression inducing by daidzein treatment enhanced this effect. Furthermore, we found decreased protein expression levels of Bcl-2 and Bcl-xl in daidzein treatment groups, suggesting apoptotic processes were activated, which was consistent with the results of cell cycle analysis and apoptosis assay on flow cytometry experiments in the present study.

To verify the anti-tumor effects of daidzein was directly mediated by FGFR3, we used siRNAs to knock down the ex- pression level of FGFR3 and checked whether the activity of daidzein still existed. After determining the knockdown effect of FGFR3 by Western blotting, RT112 cells were subjected to the cell viability assay as in Figure 1. As shown in Figure 4C, the FGFR3 siRNAs had notable effect to knock-down the endogenous expression of FGFR3 in RT112 cells as expected. In this case, the cell viability assay suggested that with the low expression of FGFR3, daidzein almost lost its inhibition to bladder cancer cells proliferation (Figure 4C). On the other hand, consistent with the result in Figure 4A, Figure 4D showed that daidzein decreased the phosphorylation levels of FGFR3 that was activated by FGF1 addition. Notably, we found this activity of daidzein was comparable with PD173074, a FGFR3 inhibitor. Taken together, all these results indicated that the inhibitory effect of daidzein on bladder cancer was mainly mediated by FGFR3 pathway.

\section{Discussion}

Over $70 \%$ of anti-tumor drugs developed in the last three decades are natural products[16]. Daidzein belongs to the isoflavone subclass of flavonoids and is widely found in soy based products. Previously, it was reported that daidzein was used as a phytoestrogen for menopausal-related disorders $[10,11]$.In addition, daidzein has effects on brain function [17], alcohol abuse [18] and directly dilates arteries in vitro [19]. Guo and his colleagues [14] have shown that daidzein can affect human cervical cancer Hela cells on cell growth, cell cycle, and telomerase activity in vitro at the concentra- 


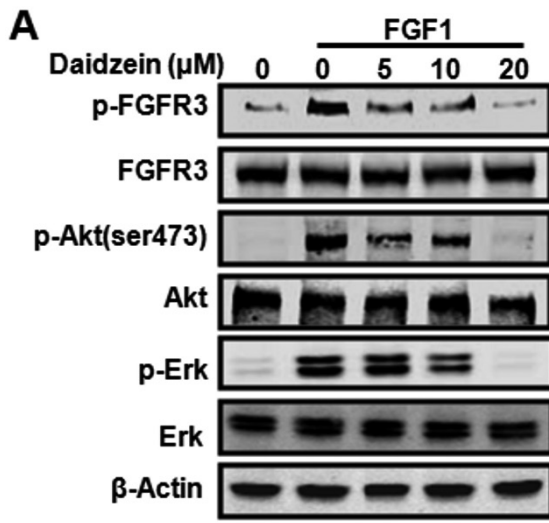

B

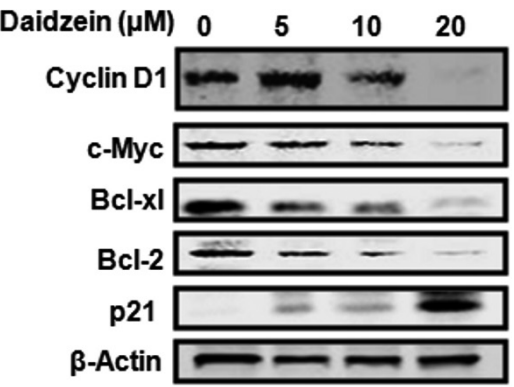

C

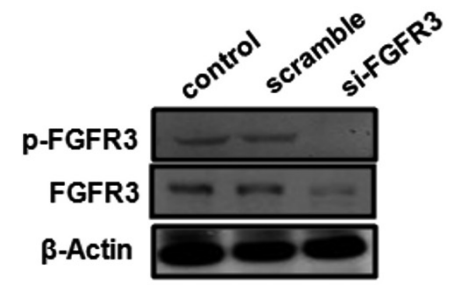

D
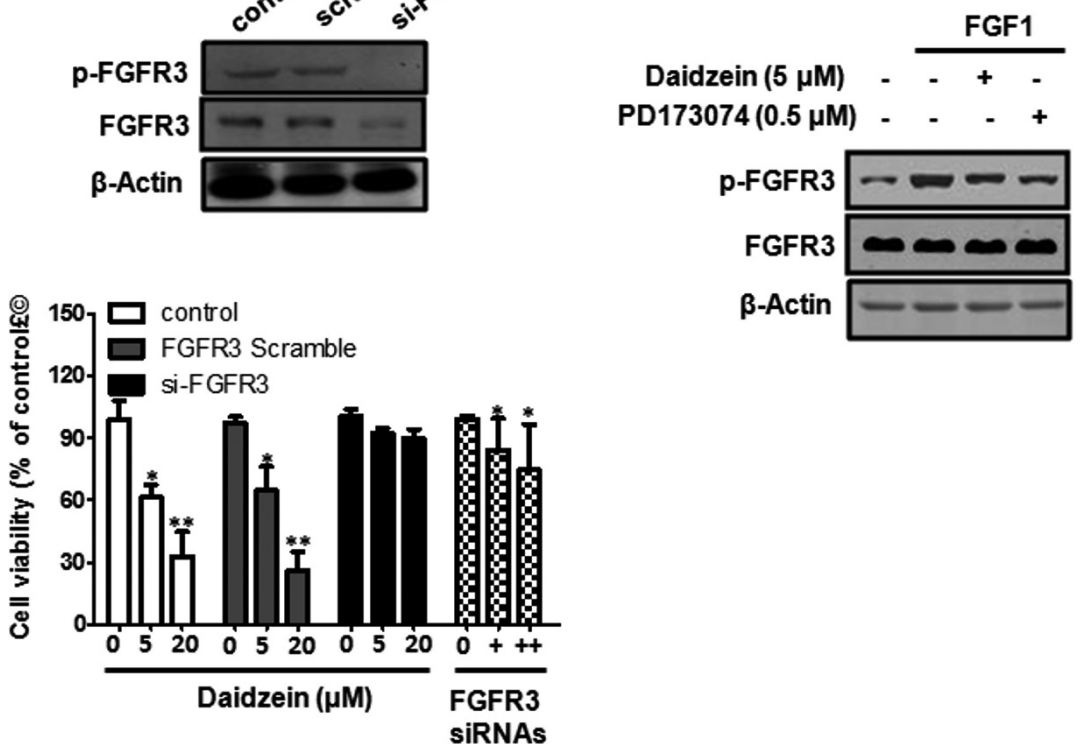

Figure 4. Daidzein suppresses bladder cancer growth through inhibiting the FGFR3 signaling pathway. (A) Suppression by daidzein of FGF1-induced phosphorylation of Akt and Erk in RT112 cells. Cells were pretreated with indicated concentrations of daidzein for 4 hours, and then incubated with $20 \mathrm{ng} / \mathrm{ml}$ of FGF1 for another 1 hour and subjected to the western blotting analysis with indicated antibodies. $\beta$-actin served as a loading control. (B) The endogenous protein levels of several key regulators involved in cell cycle andcell apoptosis process were influenced under daidzein treatments. The cells were treated indicated then cell lysates were subjected to western blotting analysis with indicated antibodies.

(C) RT112 cells were transiently transfected with FGFR3-siRNAs or the non-targeting scrambled siRNA for 48 hours and the interference effect of FGFR3 was detected by Western blotting. Cells were treated with daidzein $(0,5$ and $20 \mu \mathrm{M})$ for another 48 hours and cell viability was tested by CCK-8 detection kit.

(D) Suppression of FGFR3 pathway by PD173074 and daidzein in RT112 cells. Cells were pretreated with indicated concentrations of PD173074 and daidzein for 4 hours, and then incubated with $20 \mathrm{ng} / \mathrm{ml}$ of FGF1 for another 1 hour and subjected to the western blotting analysis with indicated antibodies. $\beta$-actin served as a loading control.

tions from 6.25 to $100 \mu \mathrm{M}$. Another group reported that the invasive capacity of breast cancer MDA-MB-231 cells was significantly reduced with $50 \mu \mathrm{M}$ daidzein treatment in part via the down-regulation of MMP-2 expression[13]. However, its various biological properties cannot be totally explained by regulation of MMP-2 protein, and its anti-tumor potential remains to be determined. In this study, we found that daidzein inhibited the growth of a variety of human bladder cancer cells (RT112 cells, RT4 cells, SW780 cells)in a time- and dose-dependent manner. The $\mathrm{IC}_{50}$ value for daidzein inhibition of indicated bladder carcinoma cells ranged from5to $10 \mu \mathrm{M}$. We also performed the cell viability of daidzein on normal human urothelial cells, SV-HUC-1 cells. The result showed that the $\mathrm{IC}_{50}$ value on SV-HUC-1 cells was much more than $100 \mu \mathrm{M}$, indicating the selectivity of daidzein toward cancer cells. Similarly, in the colony formation experiment, we found daidzein inhibited colony formation of different bladder cancer cells. 
To further determine whether the anti-proliferative effect of daidzein is due to the inhibition of cellcycle progression or the induction of apoptosis, we carried out a flow cytometric analysis of the cell cycle in RT112 cells. Our data showed daidzein altered the cell cycle distribution and arrested cells at G1/S phase. Interestingly, flow cytometric analysis from other study [14]demonstrated human cervical cancer Hela cells were arrested at G1 or G2 /M phase with daidzein treatment. This indicates that different types of tumor cell lines respond differently to daidzein's treatment, and multiple mechanisms might be responsible for cell cycle arrest in various cancer cells. AnnexinV-FITC/PI staining results suggested daidzein could activate the apoptosis process and lead to cell death induction in RT112 cells. In further in vivo study, we tested efficacy of daidzein on pre-established subcutaneous xenografts of RT112 cells in nude mice. The administration of daidzein halted the growth of human bladder tumor xenografts derived from RT112 cell lines.

Previous work identified that increased FGFR3 expression was associated with poor and decreased postoperative patient survival in a significant proportion of bladder cancer cases $[8$, 20]. Furthermore, somatic activating mutations in FGFR3 have been identified in $60 \%-70 \%$ of papillary and $16 \%-20 \%$ of muscle-invasive bladder cancer [21, 22].Hence, theFGFR3 signaling pathway is a potential oncogenic driver and therapeutic target in bladder cancer. Our western blotting results suggested that daidzein decreased the phosphorylation level of FGFR3 protein. Akt and Erk, as two major downstream kinase proteins responsible for FGFR3 signaling pathways, play key roles in apoptosis, cell proliferation, transcription and cell migration during tumogenesis and the progression of cancer. Under various circumstances, activation of Akt (P-Akt) and Erk (P-Erk) were shown to overcome cell cycle arrest, we found that daidzein could block the activation of Akt and Erk induced by FGF1 treatment. In this study, we used siRNAs and antagonist to inhibit the activation of FGFR3 and found that the function model of daidzein was similar with PD173074 and was also mediated by FGFR3 pathway. Our results proved that the FGFR3 pathway was essential for daidzein's anti-cancer activity and daidzein exerted its function through this carcinogenic pathway, which supported evidences that daidzein might have great potential in the research and development of bladder cancer therapy.

Cyclin D1 is a critical cell cycle regulatory protein, playing an important role in the G1/S transition through binding to cyclin-dependent kinase 4 (CDK4)to phosphorylate [23] and inactivate the retinoblastoma $(\mathrm{Rb})$ protein [24]. Previous studies showed that increased CyclinD1 expression was associated with poor prognosis and decreased postoperative patient survival $[25,26]$. Additionally, a significant proportion of bladder cancer cases showed that over-expression of the c-Myc gene was relevant with bladder carcinogenesis as well [27-29].In this study, we detected Cyclin D1 and c-Myc expression levels under daidzein treatment. Interestingly, we found daidzein decreased the expression levels of both proteins, which may be contributed to the cell cycle arrest function. On the other hand, we found another key cell cycle regulator [30, 31], p21 protein, was activated by daidzein treatment in a dose dependent manner. This result will enhance the inhibitory function of daidzein to cancer cells. Previous studies reported that changes in mitochondrial membrane potential caused the release of cytochrome $\mathrm{c}$ and apoptosis-inducing factors into the cytosol and induced apoptotic cell death $[32,33]$. Under normal situations, the Bcl-2 family, including Bcl-2 and Bcl$\mathrm{xL}$, is important for maintaining mitochondrial integrity [34, 35]. Activation of Bcl-2 and Bcl-xL were reported to prevent the mitochondrial release of cytochrome $c$, thus inhibiting the activation ofcaspases cascade and apoptosis [36, 37]. Our results showed that the expression of $\mathrm{Bcl}-2$ and $\mathrm{Bcl}-\mathrm{xL}$ were down-regulated by daidzein, suggesting that daidzeininduced apoptosis was modulated by the expression of these apoptosis-suppressing molecules. Consequently, expression of $\mathrm{Bcl}-2$ and $\mathrm{Bcl}-\mathrm{xL}$ may result in altered permeability, triggering mitochondrial cytochrome $\mathrm{c}$ release into the cytosol and activating apoptotic process.

In summary, we demonstrated the anti-tumor effects of daidzein on bladder cancer cells both in vitro and in vivo, and partially delineated the underlying molecular mechanism. Daidzein inhibited cell proliferation, induced cell cycle arrest and apoptosis of RT112 cells and suppressed cell colony formation and xenograft tumor growth in nude mice. Thus, our findings suggest that daidzein acts at least partly through inhibition of activated FGFR3 and represents a novel candidate for a chemotherapeutic agent against bladder cancer.

Acknowledgements: This work was supported by funding from Jiaxing city key discipline (04-F-18).

\section{References}

[1] FERLAY J, SOERJOMATARAM I, DIKSHIT R, ESER S, MATHERS $C$ et al. Cancer incidence and mortality worldwide: sources, methods and major patterns in GLOBOCAN 2012. Int J Cancer 2015; 136: E359-386. http://dx.doi. org/10.1002/ijc.29210

[2 ] SIEGEL R, NAISHADHAM D, JEMAL A. Cancer statistics, 2012. CA Cancer J Clin 2012; 62: 10-29. http://dx.doi. org/10.3322/caac. 20138

[3 ] RAJU R, PALAPETTA SM, SANDHYA VK, SAHU A, ALIPOOR A et al. A Network Map of FGF-1/FGFR Signaling System. Journal of Signal Transduction 2014; 1-16. http:// dx.doi.org/10.1155/2014/962962

[4 ] ESWARAKUMAR VP, LAX I, SCHLESSINGER J. Cellular signaling by fibroblast growth factor receptors. Cytokine Growth Factor Rev 2005; 16: 139-149. http://dx.doi. org/10.1016/j.cytogfr.2005.01.001

[5 ] CHANG KW, HUANG YL, WONG ZR, SU PH, HUANG $\mathrm{BM}$ et al. Fibroblast growth factor-2 up-regulates the expression of nestin through the Ras-Raf-ERK-Sp1 signaling axis in C6 glioma cells. Biochem Biophys Res Commun 2013; 434: 854-860. http://dx.doi.org/10.1016/j.bbrc.2013.04.031 
[6 ] BEDUSSI F, BOTTINI A, MEMO M, FOX SB, SIGALA S et al. Targeting fibroblast growth factor receptor in breast cancer: a promise or a pitfall? Expert Opin Ther Targets 2014; 18: 665-678. http://dx.doi.org/10.1517/14728222.2014.898064

[7 ] SMAL MP, ROLEVICH AI, POLYAKOV SL, KRASNY SA, GONCHAROVA RI. FGFR3 and TP53 mutations in a prospective cohort of Belarusian bladder cancer patients. Exp Oncol 2014; 36: 246-251.

[8 ] TOMLINSON DC, BALDO O, HARNDEN P, KNOWLES MA. FGFR3 protein expression and its relationship to mutation status and prognostic variables in bladder cancer. J Pathol 2007; 213: 91-98. http://dx.doi.org/10.1002/path.2207

[9] WILLIAMS SV, HURST CD, KNOWLES MA. Oncogenic FGFR3 gene fusions in bladder cancer. Hum Mol Genet 2013; 22: 795-803. http://dx.doi.org/10.1093/hmg/dds486

[10 ] GOTTSTEIN N, EWINS BA, ECCLESTON C, HUBBARD GP, KAVANAGH IC et al. Effect of genistein and daidzein on platelet aggregation and monocyte and endothelial function. Br J Nutr 2003; 89: 607-616. http://dx.doi.org/10.1079/ BJN2003820

[11 ] HINTZ KK, REN J. Phytoestrogenic isoflavones daidzein and genistein reduce glucose-toxicity-induced cardiac contractile dysfunction in ventricular myocytes. Endocr Res 2004; 30: 215-223. http://dx.doi.org/10.1081/ERC-120037730

[12 ] ZHAO XH, YANG ZQ, BAO LB, WANG CY, ZHOU $S$ et al. Daidzein enhances intramuscular fat deposition and improves meat quality in finishing steers. Exp Biol Med (Maywood) 2015; 240:1152-1157. http://dx.doi. org/10.1177/1535370214564755

[13 ] MAGEE PJ, ALLSOPP P, SAMALETDIN A,. Rowland IR. Daidzein, R-(+)equol and S-(-)equol inhibit the invasion of MDA-MB-231 breast cancer cells potentially via the downregulation of matrix metalloproteinase-2. Eur J Nutr 2014; 53:345-350. http://dx.doi.org/10.1007/s00394-013-0520-z

[14 ] GUO JM, KANG GZ, XIAO BX, LIU DH, ZHANG S. Effect of daidzein on cell growth, cell cycle, and telomerase activity of human cervical cancer in vitro. Int J Gynecol Cancer 2004; 14: 882-888. http://dx.doi.org/10.1111/j.1048-891$\underline{X .2004 .14525 . \mathrm{x}}$

[15 ] MIYAKE M, ISHII M, KOYAMA N, KAWASHIMA K, KODAMA T et al. 1-tert-butyl-3-[6-(3,5-dimethoxyphenyl)-2-(4-diethylamino-butylamino)-pyrido[2,3 -d] pyrimidin-7-yl]-urea (PD173074), a selective tyrosine kinase inhibitor of fibroblast growth factor receptor-3 (FGFR3), inhibits cell proliferation of bladder cancer carrying the FGFR3 gene mutation along with up-regulation of p27/Kip1 and G1/ G0 arrest. J Pharmacol Exp Ther 2010; 332:795-802. http:// dx.doi.org/10.1124/jpet.109.162768

[16 ] KARIKAS GA. Anticancer and chemopreventing natural products: some biochemical and therapeutic aspects. J BUON 2010; 15: 627-638.

[17 ] KOUKI T, KISHITAKE M, OKAMOTO M, OOSUKA I, TAKEBE $\mathrm{M}$ et al. Effects of neonatal treatment with phytoestrogens, genistein and daidzein, on sex difference in female rat brain function: estrous cycle and lordosis. Horm Behav 2003; 44:140-145. http://dx.doi.org/10.1016/S0018-506$\underline{\mathrm{X}(03) 00122-3}$
[18 ] NAKAGAWA K, ADACHI J, WONG MC, UENO Y. Protective effect of daidzein against acute ethanol-induced lipid peroxidation in rat jejunum. Kobe J Med Sci 2006; 52: 141-149.

[19 ] SATO A, HATTORI Y, KANNO M. Effects of genistein and daidzein on enhanced vascular contractile reactivity and $\mathrm{Ca} 2+$ sensitivity in cardiomyopathic hamsters. Methods Find Exp Clin Pharmacol 2000; 22: 25-30. http://dx.doi.org/10.1358/ $\underline{\text { mf.2000.22.1.795816 }}$

[20 ] VAN RHIJN BW, MONTIRONI R, ZWARTHOFF EC, JOBSIS AC, VAN DER KWAST TH. Frequent FGFR3 mutations in urothelial papilloma. J Pathol 2002; 198: 245-251. http:// dx.doi.org/10.1002/path.1202

[21 ] MARTINEZ-TORRECUADRADA J, CIFUENTES G, LOPEZ-SERRA P, SAENZ P, MARTINEZ A et al. Targeting the extracellular domain of fibroblast growth factor receptor 3 with human single-chain Fv antibodies inhibits bladder carcinoma cell line proliferation. Clin Cancer Res 2005; 11: 6280-6290. http://dx.doi.org/10.1158/1078-0432.CCR-05$\underline{0282}$

[22 ] MARTINEZ-TORRECUADRADA JL, CHEUNG LH, LOPEZ-SERRA P, BARDERAS R, CANAMERO $\mathrm{M}$ et al. Antitumor activity of fibroblast growth factor receptor 3-specific immunotoxins in a xenograft mouse model of bladder carcinoma is mediated by apoptosis. Mol Cancer Ther 2008; 7: 862-873. http://dx.doi.org/10.1158/1535-7163.MCT-07$\underline{0394}$

[23 ] CIZNADIJA D, LIU Y, PYONTECK SM, HOLLAND EC, KOFF A. Cyclin D1 and cdk4 mediate development of neurologically destructive oligodendroglioma. Cancer Res 2011; 71:6174-6183. http://dx.doi.org/10.1158/0008-5472.CAN-11$\underline{1031}$

[24 ] SHEN J, ZHANG S, LI Y, ZHANG W, CHEN J et al. p14(ARF) inhibits the functions of adenovirus E1A oncoprotein. Biochem J 2011; 434:275-285. http://dx.doi.org/10.1042/ BJ20101163

[25 ] REN B, LI W, YANG Y, WU S. The impact of cyclin D1 overexpression on the prognosis of bladder cancer: a metaanalysis. World J Surg Oncol 2014;12: 55. http://dx.doi. org/10.1186/1477-7819-12-55

[26 ] LIN DI, LESSIE MD, GLADDEN AB, BASSING CH, WAGNER KU et al. Disruption of cyclin D1 nuclear export and proteolysis accelerates mammary carcinogenesis. Oncogene 2008; 27: 1231-1242. http://dx.doi.org/10.1038/ sj.onc. 1210738

[27 ] JEONG KC, KIM KT, SEO HH, SHIN SP, AHN KO et al. Intravesical instillation of c-MYC inhibitor KSI-3716 suppresses orthotopic bladder tumor growth. J Urol 2014; 191:510-518. http://dx.doi.org/10.1016/j.juro.2013.07.019

[28 ] SHIINA H, IGAWA M, SHIGENO K, TERASHIMA M, DEGUCHI $\mathrm{M}$ et al. Beta-catenin mutations correlate with over expression of C-myc and cyclin D1 Genes in bladder cancer. J Urol 2002; 168: 2220-2226. http://dx.doi.org/10.1016/ $\underline{\text { S0022-5347(05)64359-5 }}$

[29] WATTERS AD, LATIF Z, FORSYTH A, DUNN I, UNDERWOOD MA et al. Genetic aberrations of c-myc and CCND1 in the development of invasive bladder cancer. 
Br J Cancer 2002; 87: 654-658. http://dx.doi.org/10.1038/ sj.bjc. 6600531

[30 ] SHEN J, SHENG X, CHANG ZN, WU Q, WANG S et al. Keeping mammalian mutation load in check: regulation of the activity of error-prone DNA polymerases by p53 and p21. Cell Rep 2014; 7:180-193. http://dx.doi.org/10.1016/j. celrep.2014.02.042

[31 ] WANG C, CHEN Z, GE Q, HU J, LI F et al. Up-regulation of p21(WAF1/CIP1) by miRNAs and its implications in bladder cancer cells. FEBS Lett 2014; 588: 4654-4664. http://dx.doi. org/10.1016/j.febslet.2014.10.037

[32 ] YANG J, LIU X, BHALLA K, KIM CN, IBRADO AM et al. Prevention of apoptosis by Bcl-2: release of cytochrome $\mathrm{c}$ from mitochondria blocked. Science 1997; 275: 1129-1132. http:// dx.doi.org/10.1126/science.275.5303.1129

[33 ] GARRIDO C, GALLUZZI L, BRUNET M, PUIG PE, DIDELOT C et al. Mechanisms of cytochrome $c$ release from mitochondria. Cell Death Differ 2006; 13: 1423-1433. http:// dx.doi.org/10.1038/sj.cdd.4401950

[34 ] ANTONSSON B, MARTINOU JC. The Bcl-2 protein family. Exp Cell Res 2000; 256: 50-57. http://dx.doi.org/10.1006/ excr.2000.4839

[35 ] PARK D, MAGIS AT, LI R, OWONIKOKO TK, SICA GL et al. Novel small-molecule inhibitors of Bcl-XL to treat lung cancer. Cancer Res 2013; 73: 5485-5496. http://dx.doi. org/10.1158/0008-5472.CAN-12-2272

[36 ] SHEN J, SONG G, AN M, LI X, WU N et al. The use of hollow mesoporous silica nanospheres to encapsulate bortezomib and improve efficacy for non-small cell lung cancer therapy. Biomaterials 2014; 35: 316-326. http://dx.doi.org/10.1016/j. biomaterials.2013.09.098

[37] FISHER DE. Apoptosis in cancer therapy: crossing the threshold. Cell 1994; 78: 539-542. http://dx.doi. org/10.1016/0092-8674(94)90518-5 